\title{
Recycling water glass from wet reclamation sewage of waste sodium silicate-bonded sand
}

\author{
Li-chi Wang, *Wen-ming Jiang, Xiao-long Gong, Fu-chu Liu and Zi-tian Fan \\ State Key Lab of Materials Processing and Die \& Mould Technology, Huazhong University of Science and Technology, Wuhan 430074, China
}

\begin{abstract}
Wet reclamation of waste sodium silicate-bonded sand produces much alkaline sewage and causes pollution. Recycling water glass from wet reclamation sewage of the waste sodium silicate-bonded sand can solve pollution issues and generate economic benefits. In this work, the wet reclamation sewage was filtered, and the filtrate was causticized with a quicklime powder to produce a lye. The effects of causticization temperature, causticization time, and the amount of quicklime powder on the causticization rate were studied. The lye was used to dissolve the silica in the filtration residue to prepare a sodium silicate solution. The effects of the mass of filtration residue, dissolution temperature, and dissolution time on sodium silicate modulus were studied. Finally, the recycled water glass was obtained by concentrating the sodium silicate solution, and the bonding strength of the recycled water glass was tested. The results showed that the causticization rate could be improved by increasing the amount of quicklime powder, causticization temperature, and causticization time, and the highest causticization rate was above $92 \%$. Amorphous silica in the filtration residue dissolved in the lye. Increasing the amount of the filtration residue, dissolution temperature, and dissolution time could improve the sodium silicate modulus. The bonding strength of the recycled water glass was close to that of commercial water glass. The recycled water glass could be used as a substitute for the commercial water glass.
\end{abstract}

Key words: waste sodium silicate-bonded sand; wet reclamation; sewage treatment; causticization; recycling water glass

CLC numbers: TG221 ${ }^{+} .1 \quad$ Document code: A Article ID: 1672-6421 2019)03-198-06

Nodium silicate-bonded sand casting is popular due to its advantages including good casting quality, low cost, and non-toxicity ${ }^{[1-2]}$. Currently, millions of tons of waste sodium silicate-bonded sand are produced in China every year, and cause serious environmental problems if not properly treated $^{[3]}$. The waste sodium silicate-bonded sand can partially replace ordinary sand for concrete or it can be used as building filler ${ }^{[4-6]}$, but as the amount of the waste sodium silicate-bonded sand is great, most of it still needs to be reused. The waste sodium silicate-bonded sand should be reclaimed before reuse. Reclaiming the waste sodium silicatebonded sand refers to removing the impurities such as residual binder on the surfaces of the waste sand

\section{*Wen-ming Jiang}

Male, born in 1982, Associate professor. Research interests: casting materials and technology, light alloy and composite materials. He has published more than 70 papers.

E-mail: wmjiang@hust.edu.cn

Received: 2018-11-29; Accepted: 2019-01-24 grains to regain a state close to that of new sand Currently, the main methods for reclaiming the waste sodium silicate-bonded sand are wet reclamation and dry reclamation ${ }^{[1-3,7-9]}$. The reclaimed sand obtained by wet reclamation is better than that obtained by dry reclamation in quality, and can directly replace the new sand ${ }^{[10]}$. Wet reclamation refers to transferring the impurities from the surfaces of the waste sand grains into water, and then separating the sand grains and the water to remove the impurities. However, wet reclamation produces much alkaline sewage, which has to be well treated. If the problem of the wet reclamation sewage is solved, wet reclamation will be an environmentally friendly way to reclaim the waste sodium silicate-bonded sand.

Water glass (sodium silicate) is used as a binder in the sodium silicate-bonded sand casting, and is usually hardened with carbon dioxide or esters. Therefore, the impurities on the surfaces of the waste sand grains mainly include sodium carbonate, sodium hydrogencarbonate, sodium acetate (hardened with esters), and sodium silicate, and cause the wet 
reclamation sewage to be alkaline. At present, the treatment process of wet reclamation sewage includes neutralizing, and then precipitating or filtering ${ }^{[11-12]}$. The treated sewage contains many soluble salts and will cause environmental problems if directly discharged ${ }^{[13]}$. During the wet reclamation process, most of the binder components enter into the water. Recycling water glass from the wet reclamation sewage can solve environmental problems and generate economic benefits.

In this work, aiming at recycling water glass from the wet reclamation sewage of waste sodium silicate-bonded sand, the wet reclamation sewage was first filtered, and the filtrate was causticized $^{[14-15]}$ with a quicklime powder and then converted into a lye. The effects of causticization temperature, causticization time, and the amount of quicklime powder on the causticization rate were investigated. The lye was used to dissolve the filtration residue, and a low concentration sodium silicate solution and a dissolution residue were obtained after the filtration. The effects of the filtration residue to lye ratio, dissolution temperature, and dissolution time on the sodium silicate modulus were studied. The XRD analysis and component analysis of the filtration residue and the dissolution residue were performed. Finally, the recycled water glass was obtained by concentrating the low concentration sodium silicate solution. The bonding strengths of the recycled water glass and commercial water glass were measured.

\section{Experimental procedure}

\subsection{Process of recycling water glass}

Figure 1 shows the process of recycling water glass from the wet reclamation sewage. After the quicklime powder is added into the filtrate, the following reactions occur:

$$
\begin{aligned}
& \mathrm{CaO}+\mathrm{H}_{2} \mathrm{O}=\mathrm{Ca}(\mathrm{OH})_{2} \\
& \mathrm{Ca}(\mathrm{OH})_{2}+\mathrm{Na}_{2} \mathrm{CO}_{3}=\mathrm{CaCO}_{3} \downarrow+2 \mathrm{NaOH} \\
& \mathrm{NaHCO} \mathrm{NaOH}_{3}+\mathrm{NaOH}_{2} \mathrm{CO}_{3}+\mathrm{H}_{2} \mathrm{O} \\
& \mathrm{Ca}(\mathrm{OH})_{2}+\mathrm{Na}_{2} \mathrm{SiO}_{3}=\mathrm{CaSiO}_{3} \downarrow+2 \mathrm{NaOH}
\end{aligned}
$$

where equation (1) is the digestion reaction, and equation (2) is the causticization reaction. After the lye is mixed with the filtration residue, the following reaction occurs:

$$
\mathrm{SiO}_{2}+2 \mathrm{NaOH}=\mathrm{Na}_{2} \mathrm{SiO}_{3}
$$

\subsection{Materials}

The sewage used in the experiment was the wet reclamation sewage of waste sodium silicate-bonded sand hardened with carbon dioxide. The sewage had been filtered using filter membranes with a mean pore diameter of $5 \mu \mathrm{m}$, and the filtration residue was dried at $110^{\circ} \mathrm{C}$ and then ground. Table 1 shows the main solutes in the filtrate. The sodium silicate in the filtrate is in a low concentration and can be ignored. Table 2 shows the main components of the filtration residue, and Fig. 2 shows the XRD analysis results of the filtration residue. The calcium carbonate and alumina in the filtration residue were derived from the waste sodium silicate-bonded sand. The effective $\mathrm{CaO}$ content of the quicklime powder was

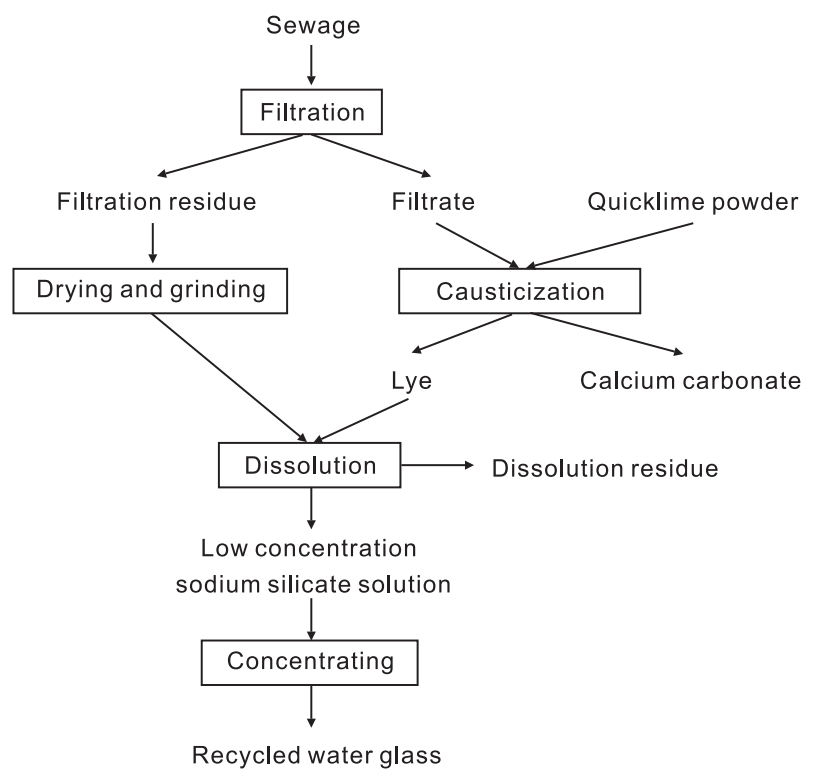

Fig. 1: Flow chart for recycling water glass from wet reclamation sewage

Table 1: Main solutes in filtrate

\begin{tabular}{cccc|}
\hline Solute & $\mathrm{Na}_{2} \mathrm{CO}_{3}$ & $\mathrm{NaHCO}_{3}$ & $\mathrm{Na}_{2} \mathrm{SiO}_{3}$ \\
\hline Concentration $\left(\mathrm{g} \cdot \mathrm{L}^{-1}\right)$ & 92.9 & 31.7 & $<1$
\end{tabular}

Table 2: Main components in filtration residue (wt.\%)

$\begin{array}{lllllllll}\mathrm{Si} & \mathrm{Ca} & \mathrm{Na} & \mathrm{Zr} & \mathrm{Fe} & \mathrm{Al} & \mathrm{K} & \mathrm{Mg}\end{array}$

$\begin{array}{llllllll}72.2303 & 8.3843 & 6.4956 & 3.8354 & 3.5366 & 2.8052 & 0.8927 & 0.4561\end{array}$

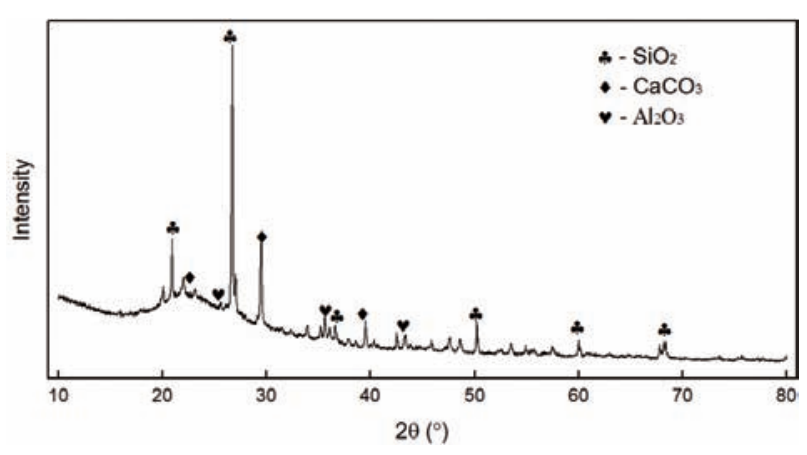

Fig. 2: XRD pattern of filtration residue

$95 \%$. The other reagents used were of analytical reagent grade. Da-lin sand at 50-100 mesh, commercial sodium silicate (modulus 2.19 , density $1.54 \mathrm{~g} \cdot \mathrm{mL}^{-1}$ ), and commercial ester were used in the bonding strength test.

\subsection{Methods}

\subsubsection{Causticization}

The filtrate $(100.0 \mathrm{~mL})$ was put into a beaker, and the beaker was put in a water bath and heated to $30-90{ }^{\circ} \mathrm{C}$. The quicklime 
powder (7.4-9.6 g) was added into the filtrate and the mixture was stirred for 1-15 min. The mixture was at last filtered. The lye obtained was titrated to measure the normality of sodium hydroxide and sodium carbonate with phenolphthalein and methyl orange as indicators. The efficiency of the causticizing process was evaluated by the causticization rate, which was calculated as follows:

$$
\text { Causticization rate }=\frac{N_{\text {NaOH }}}{N_{\text {NaOH }}+N_{\mathrm{Na}_{2} \mathrm{CO}_{3}}}
$$

where $N_{\text {ман }}$ is the normality of sodium hydroxide in the lye, and $N_{\mathrm{Na}_{3} \mathrm{CO},}$ is the normality of sodium carbonate in the lye.

\subsubsection{Dissolution}

The lye $(30.0 \mathrm{~mL})$ and the filtration residue $(6-15 \mathrm{~g})$ were added into a beaker and mixed. The beaker was then bathed at $50-90{ }^{\circ} \mathrm{C}$ for $10-60 \mathrm{~min}$. The mixture was filtered at last and a low concentration sodium silicate solution and a dissolution residue were obtained. The modulus of sodium silicate solution was measured. The dissolution residue was washed, dried, and ground. The dissolution residue was subjected to XRD analysis and component analysis using an X-ray diffractometer (XRD, Empyrean, PANalytical B.V., Holland) and a wavelength dispersive X-ray fluorescence spectrometer (WD-XRF, XRF1800, Shimadzu, Japan), respectively.

\subsubsection{Bonding strength test}

The recycled water glass was obtained by concentrating the low concentration sodium silicate solution. The bonding strengths of the recycled water glass were measured and the bonding strengths of the commercial water glass with the same modulus and density were also measured for comparison. The Da-lin sand and the commercial ester were mixed in a sand mixer for $60 \mathrm{~s}$, and then the water glass was added into the mixer and mixed for $30 \mathrm{~s}$. The commercial ester used was $0.3 \%$ of the Da-lin sand by mass, and the water glass used was $3 \%$ of the Da-lin sand by mass. The mixture was made into cylindrical samples (30 $\mathrm{mm}$ in diameter and $30 \mathrm{~mm}$ in height) and the compressive strengths of the samples were measured.

\section{Results and discussion}

\subsection{Causticization}

\subsubsection{Effect of causticization temperature on causticization rate}

The amount of quicklime powder was indicated as the ratio of the amount of effective calcium oxide in the quicklime powder to theoretical demand $\left[n(\mathrm{CaO}): n\left(\mathrm{Na}_{2} \mathrm{CO}_{3}+\mathrm{NaHCO}_{3}\right)\right]$, which was $1.2: 1$ in this experiment, and the causticization time was 15 min. As shown in Fig. 3, the causticization rate increases with increasing the causticization temperature. When the causticization temperature is below $60{ }^{\circ} \mathrm{C}$, the causticization rate is below $50 \%$, and the causticization rate is about $90 \%$ when the causticization temperature is over $70{ }^{\circ} \mathrm{C}$. When the causticization temperature is low, the digestion reaction proceeds slowly, and the calcium carbonate precipitates generated by the causticization reaction cover the quicklime powder and stop the digestion reaction. Therefore, the digestion reaction cannot proceed thoroughly, and the causticization rate is low in the lack of calcium hydroxide. When the causticizing temperature gets high, the digestion reaction is fast, making it difficult for the calcium carbonate precipitates to cover the quicklime powder in time. So the digestion reaction proceeds relatively thoroughly and increases the causticization rate. Since the causticization reaction is reversible, the causticization rate cannot reach $100 \%$.

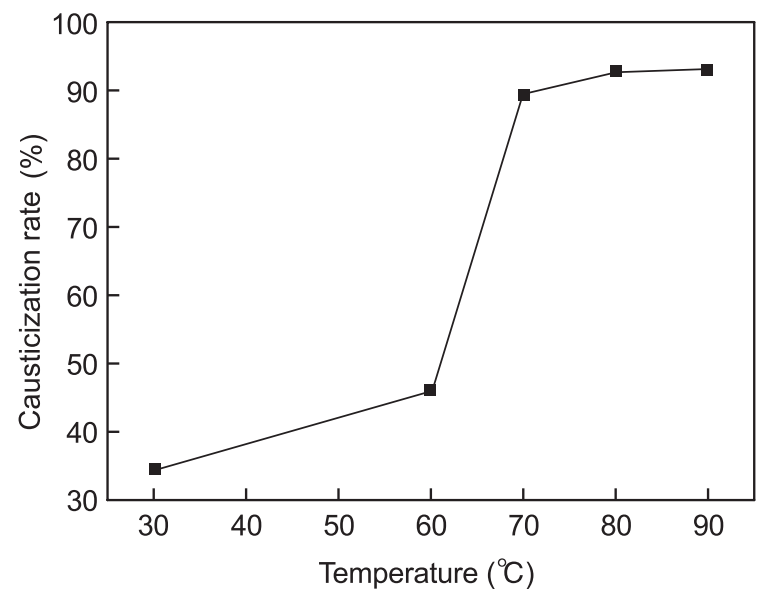

Fig. 3: Effect of causticization temperature on causticization rate

\subsubsection{Effect of causticization time on causticization rate}

As shown in Fig. 4, the causticization rate for $90{ }^{\circ} \mathrm{C}$ rises to $92.2 \%$ in $3 \mathrm{~min}$, and then reaches $93.0 \%$ in $15 \mathrm{~min}$, indicating the causticization reaction is basically completed in $3 \mathrm{~min}$ at $90{ }^{\circ} \mathrm{C}$. The causticization rate for $80{ }^{\circ} \mathrm{C}$ reaches $82.8 \%$ in $3 \mathrm{~min}$, and then rises to $92.8 \%$ in $15 \mathrm{~min}$, which means $15 \mathrm{~min}$ is needed for the causticization reaction to complete at $80{ }^{\circ} \mathrm{C}$. The heat released by the digestion reaction at $90{ }^{\circ} \mathrm{C}$ boils the filtrate, making it difficult for the calcium carbonate precipitates to cover the quicklime powder, so the digestion reaction proceeds rapidly. The filtrate is not boiled by the digestion reaction at $80{ }^{\circ} \mathrm{C}$, so the calcium carbonate precipitates slow the digestion reaction down. Therefore, the causticization reaction takes a longer time to

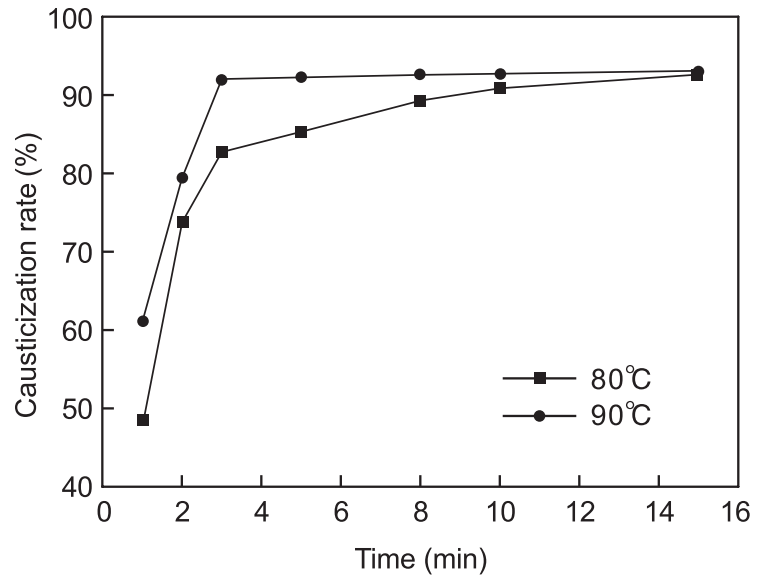

Fig. 4: Effect of causticization time on causticization rate 
complete. The causticization temperature should be $90{ }^{\circ} \mathrm{C}$ and the causticization time should be $3 \mathrm{~min}$, so that a high causticization rate can be achieved within a short time.

\subsubsection{Effect of amount of quicklime powder on causticization rate}

As shown in Fig. 5, when the amount of quicklime powder is 1:1 (theoretical demand), the causticization rate is just $81.1 \%$. The digestion reaction cannot be thorough because of the calcium carbonate precipitates when it happens in the filtrate, so the causticization reaction is not thorough in lack of calcium hydroxide. As the amount of quicklime powder increases, more calcium hydroxide is produced by the digestion reaction and the causticization rate increases. As the causticization rate does not change much when the amount of quicklime powder rise from $1.2: 1$ to $1.3: 1$, the amount of quicklime powder should be $1.2: 1$, so that the quicklime powder can be saved.

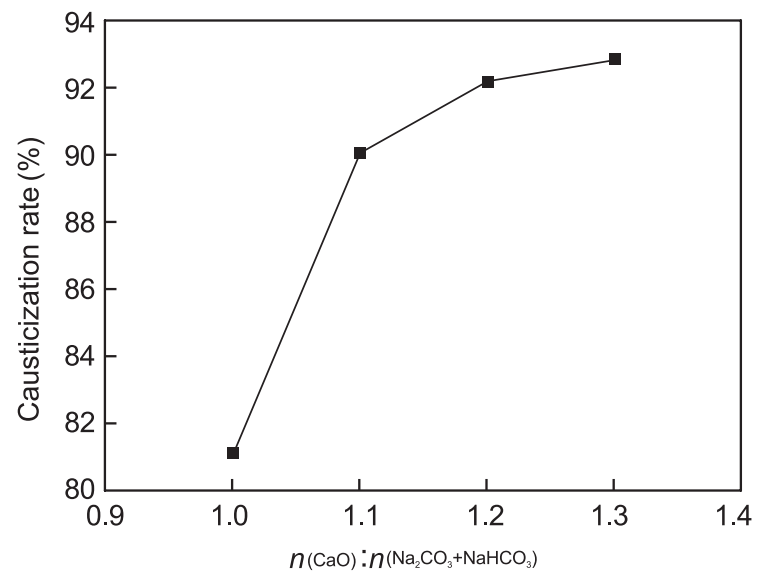

Fig. 5: Effect of amount of quicklime powder on causticization rate

\subsection{Dissolution}

\subsubsection{Effect of mass of filtration residue on sodium silicate modulus}

The dissolution temperature was $90{ }^{\circ} \mathrm{C}$ and the dissolution time was $1 \mathrm{~h}$ in this experiment. As shown in Fig. 6, as the mass of filtration residue increases, the sodium silicate modulus increases from 1.12 for $6 \mathrm{~g}$ to 2.25 for $15 \mathrm{~g}$, and the sodium silicate modulus is roughly proportional to the mass of filtration residue, indicating that the proportion of silica dissolved in the filtration residue is substantially unchanged. When the mass of filtration residue is $15 \mathrm{~g}$, the sodium silicate modulus is 2.25 , which is within the range of sodium silicate modulus commonly used in casting. Therefore, in the subsequent experiments, the mass of the filtration residue was $15 \mathrm{~g}$.

\subsubsection{Effect of dissolution temperature on sodium silicate modulus}

The dissolution time was $1 \mathrm{~h}$ in this experiment. As shown in Fig. 7, the sodium silicate modulus increases from 0.97

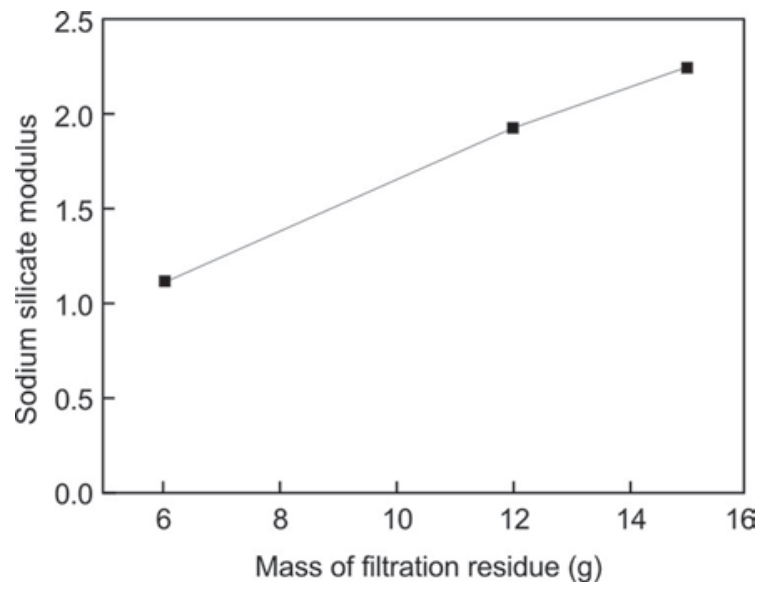

Fig. 6: Effect of mass of filtration residue on sodium silicate modulus

to 2.25 with increasing the dissolution temperature from $50{ }^{\circ} \mathrm{C}$ to $90{ }^{\circ} \mathrm{C}$. The dissolution of silica in the lye is slow at a low temperature, so not much silica is dissolved within $1 \mathrm{~h}$, resulting in a low sodium silicate modulus. When the temperature gets higher, the dissolution of silica performs faster, so more silica is dissolved in $1 \mathrm{~h}$ and the sodium silicate modulus increases.

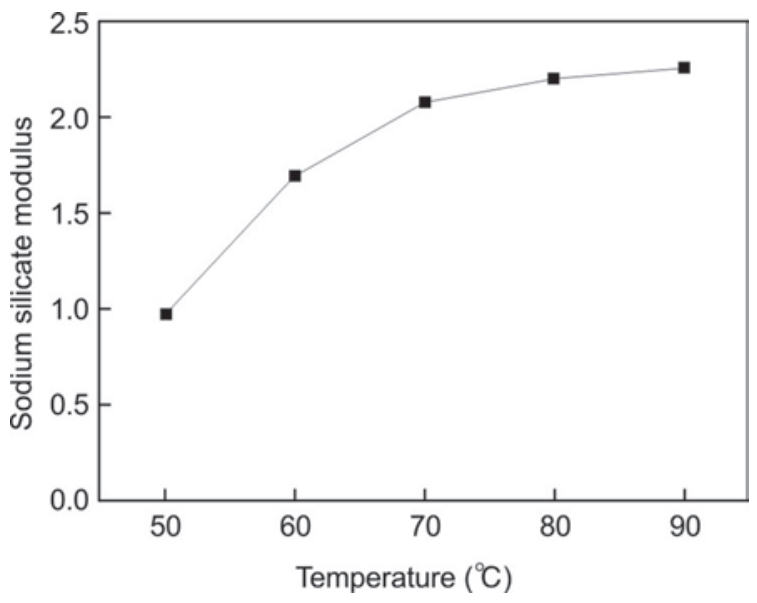

Fig. 7: Effect of dissolution temperature on sodium silicate modulus

\subsubsection{Effect of dissolution time on sodium silicate modulus}

As shown in Fig. 8, the sodium silicate modulus rapidly rises to 2.19 in $20 \mathrm{~min}$ and only reaches 2.25 in $60 \mathrm{~min}$ at $90{ }^{\circ} \mathrm{C}$; while the sodium silicate modulus rises to 2.00 in $20 \mathrm{~min}$ and reaches 2.19 in $60 \mathrm{~min}$ at $80{ }^{\circ} \mathrm{C}$. It is indicated that the dissolution of silica occurs mainly in the first $20 \mathrm{~min}$ at high temperatures. The dissolution temperature should be $90{ }^{\circ} \mathrm{C}$ and the dissolution time should be $20 \mathrm{~min}$. The sodium silicate modulus in this condition is 2.19 , which is still in the range of sodium silicate modulus commonly used in casting.

\subsubsection{Analysis of dissolution process}

Table 3 shows the content of the main elements in the 


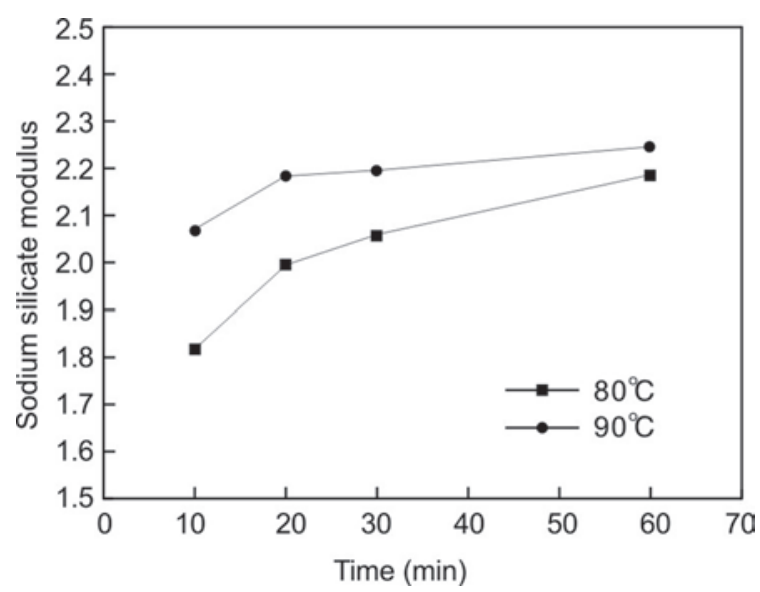

Fig. 8: Effect of dissolution time on sodium silicate modulus dissolution residue. Figure 9 shows XRD patterns of amorphous silica, the filtration residue, and the dissolution residue. The comparison between Fig. 9(a) and (b) shows that the filtration residue contains amorphous silica in addition to crystalline substances. The comparison between Figs. 9(b) and (c) shows that the dissolution residue is substantially free of amorphous silica and contains the same crystalline substances as the filtration residue, indicating that the amorphous silica in the filtration residue is dissolved during the dissolution process while the crystalline substances are not. The comparison between Table 2 and Table 3 shows that the content of silicon in the dissolution residue is significantly less than that in the filtration residue, while the content of other elements except for silicon and sodium rises to more than twice the amount in the filtration residue. The decrease in the content of sodium in

Table 3: Contents of main elements in dissolution residue (wt.\%)

\begin{tabular}{cccccccccc} 
Element & Si & Ca & Zr & Fe & Al & Na & K \\
\hline wt. \% & 47.2138 & 19.0259 & 9.0505 & 7.7499 & 7.0701 & 4.0753 & 1.7652 & 1.3665 \\
\hline
\end{tabular}

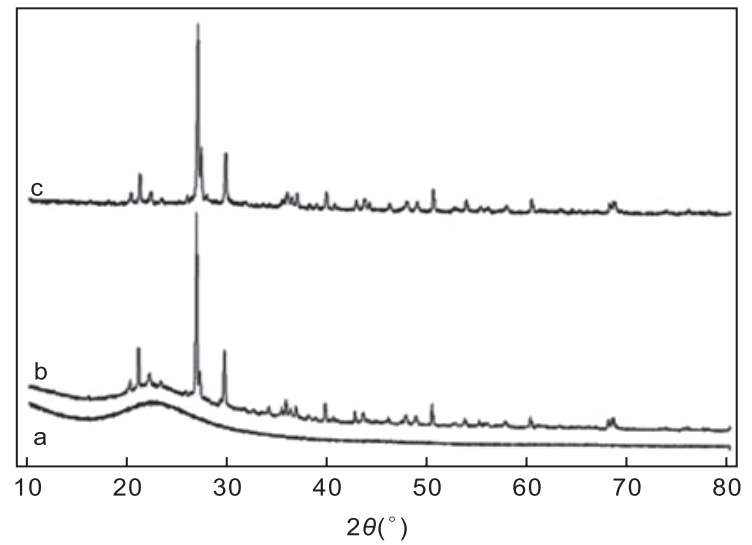

Fig. 9: XRD patterns of (a) amorphous silica, (b) filtration residue, and (c) dissolution residue

the dissolution residue is due to the fact that soluble sodium salts were washed away when the dissolution residue was washed. Therefore, the substance dissolved in the lye is mainly amorphous silica.

\subsection{Bonding strength}

The recycled water glass was prepared by concentrating the low concentration sodium silicate solution (modulus 2.19 ) obtained in the dissolution experiment to a density of $1.54 \mathrm{~g} \cdot \mathrm{mL}^{-1}$. The moduli and densities of the recycled water glass and the commercial water glass are the same. Figure 10 shows the recycled water glass and the commercial water glass. The recycled water glass is brown because the waste sodium silicate-bonded sand contains soluble colored impurities, which are dissolved in the wet reclamation sewage. The colored impurities cannot be removed by filtration and causticization, resulting in coloration of the recycled water glass.

As shown in Fig. 11, the bonding strength of the recycled water glass is slightly lower than that of the commercial water glass. The lye obtained by causticizing the filtrate and the filtration residue both contain sodium carbonate, so the recycled water glass contains sodium silicate, which may affect the bonding strength of the recycled water glass. The results in Fig. 11 show that the sodium carbonate has little effect on the bonding strength of the recycled water glass. Therefore, the recycled water glass can be used as a substitute for the commercial water glass.

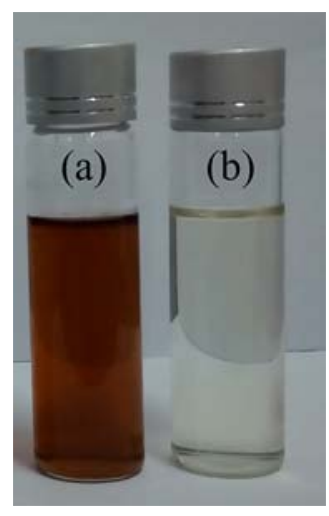

Fig. 10: (a) Recycled water glass, (b) Commercial water glass 


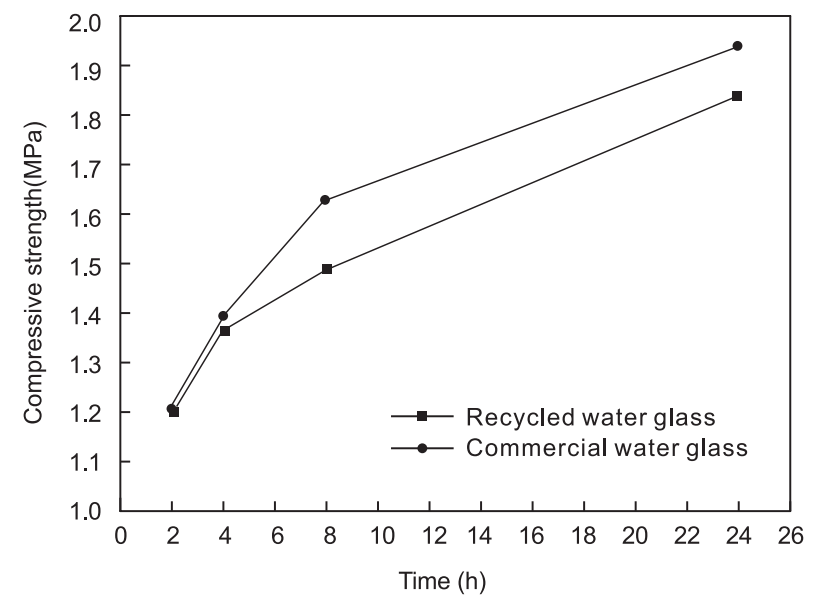

Fig. 11: Bonding strength of recycled water glass and commercial water glass

\section{Conclusions}

(1) The filtrate of the wet reclamation sewage was successfully causticized with a quicklime powder, and the highest causticization rate was over $92 \%$. The causticization rate increased with increasing the amount of quicklime powder, causticization temperature, and causticization time.

(2) The lye obtained by causticizing the filtrate of the wet reclamation sewage could dissolve amorphous silica in the filtration residue to prepare a sodium silicate solution. Increasing the mass of filtration residue, dissolution temperature, and dissolution time improved the sodium silicate modulus.

(3) The recycled water glass was obtained by concentrating the sodium silicate solution, and the bonding strength of the recycled water glass was close to that of the commercial water glass with the same modulus and density. The recycled water glass can be used as a substitute for the commercial water glass.

\section{References}

[1] Stachowicz M, Granat K. Influence of wet activation of used inorganic binder on cyclically refreshed water glass moulding sands hardened by microwaves. China Foundry, 2016, 13(6): 427-432.
[2] Wang Jina, Fan Zitian. 'Freezing-mechanical' reclamation of used sodium silicate sands. International Journal of Cast Metals Research, 2010, 23(2): 257-263.

[3] Long Wei, Fan Zitian, Li Guona. Study on application of organobentonite to wastewater disposal of wet reclaiming used sodium silicate sand. Foundry, 2012, 61(12): 1397-1400, 1404. (In Chinese)

[4] Siddique R, Singh G, Singh M. Recycle option for metallurgical by-product (spent foundry sand) in green concrete for sustainable construction. Journal of Cleaner Production, 2018, 172: 1111-1120.

[5] Yazoghli-Marzouk O, Vulcano-Greullet N, Cantegrit L, et al. Recycling foundry sand in road construction-field assessment. Construction \&Building Materials, 2014, 61: 69-78.

[6] Singh G, Siddique R. Effect of waste foundry sand (WFS) as partial replacement of sand on the strength, ultrasonic pulse velocity and permeability of concrete. Construction \& Building Materials, 2012, 26(1): 416-422.

[7] Wang Huafang, Fan Zitian, Yu Shaoqiang, et al. Wet reclamation of sodium silicate used sand and biological treatment of its wastewater by Nitzschia pales. China Foundry, 2012, 9(1): 34-38.

[8] Wang Lichi, Jiang Wenming, Liu Fuchu, et al. Investigation of parameters and mechanism of ultrasound-assisted wet reclamation of waste sodium silicate sands. International Journal of Cast Metals Research, 2018, 31: 169-176.

[9] Dańko J, Kamińska J, Skrzyńsk M. Reclamation of spent mouldingsands with inorganic binders in the vibratory reclaimerregmas. Archives of Metallurgy \& Materials, 2013, 58(3): 993-996.

[10] Xing Wanting, Liu Yue, Xin Qibin, et al. Research progress and application of reclamation for used sand. Foundry, 2015, 64(8): 735-739. (In Chinese)

[11] He Fuqiang, Fan Zitian, Wang Jina. Study of sewage treatment in wet reclamation process by used sodium silicate sand. Foundry Technology, 2008, 29: 1473-1476.(In Chinese)

[12] Ma Huilong, Li Shuzhen. A system for circle use of both wet recovery of ester cured water glass old sand and sewage. China Foundry Machinery \& Technology, 2011, 36-38. (In Chinese)

[13] Wen Jia, Dong Haoran, Zeng Guangming. Application of zeolite in removing salinity/sodicity from wastewater: A review of mechanisms, challenges and opportunities. Journal of Cleaner Production, 2018, 197: 1435-1446.

[14] Zhu Ganyu, Li Huiquan, Lin Rongyi, et al. Synthesis of superfine calcium carbonate during causticization in highly alkaline system for utilization of high-alumina fly ash. Hydrometallurgy, 2016, 165: 282-289.

[15] Yuan Bo, Wang Jing, Cai Wei, et al. Effects of temperature on conversion of $\mathrm{Li}_{2} \mathrm{CO}_{3}$ to $\mathrm{LiOH}$ in $\mathrm{Ca}(\mathrm{OH})_{2}$ suspension. Particuology, 2017, 34: 97-102. 